\title{
Association between clinical characteristics and pain relief in patients with axial spondyloarthritis treated with non-steroidal anti-inflammatory drugs
}

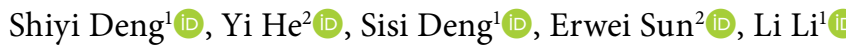 \\ ${ }^{1}$ Department of Nursing, Zhujiang Hospital, Southern Medical University, Guangzhou, China \\ ${ }^{2}$ Department of Rheumatology and Immunology, The Third Affiliated Hospital of Southern Medical University, Guangzhou, China
}

\begin{abstract}
Objectives: The aim of this study was to evaluate pain relief in axial spondyloarthritis (axSpA) patients treated with non-steroidal anti-inflammatory drugs (NSAIDs) and to investigate the relation of the demographic, clinical, and psychological characteristics with pain relief.

Patients and methods: Between February 2017 and December 2019, a total of 94 patients (61 males, 33 females; mean age: $28.3 \pm 8.1$ years; range, 14 to 54 years) who were diagnosed with axSpA and treated with NSAIDs were included. The patients were assessed at baseline and at three months. A reduction of $30 \%$ in the Numeric Rating Scale (NRS) indicates a clinically meaningful improvement. The patients were divided into the relief group ( $\geq 30 \%$ improvement in NRS) and non-relief group ( $<30 \%$ improvement). Potential influential factors for pain relief such as neuropathic pain (NP), disease activity, function, pain catastrophizing, and pain self-efficacy were assessed. The relationship between patients' characteristics and pain relief was analyzed.

Results: Seventy-two $(76.6 \%)$ patients achieved pain relief. These patients had significantly higher baseline erythrocyte sedimentation rate, C-reactive protein, and lower percentage of NP. There was no significant difference between the two groups in function, pain catastrophizing, and pain self-efficacy. Multiple logistic regression analysis revealed that patients with NP were less likely to achieve pain relief (odds ratio [OR]: 3.531, $95 \%$ confidence interval [Cl]: 1.155-10.789; $p=0.027)$.

Conclusion: Pain relief is still insufficient in some axSpA patients, despite the administration of NSAIDs. The presence of NP is significantly associated with poor pain relief. Alternative medications instead of NSAIDs are needed to achieve optimal pain relief, when NP is diagnosed.

Keywords: Axial spondyloarthritis, neuropathic pain, non-steroidal anti-inflammatory drugs, pain relief.
\end{abstract}

Axial spondyloarthritis (axSpA), including ankylosing spondylitis (AS) and non-radiographic axial spondyloarthritis (nr-axSpA), is a chronic inflammatory disease that mainly affects the axial skeleton. The reported prevalence of axSpA is between $0.32 \%$ and $1.4 \%$ in different surveys. ${ }^{1}$

Chronic back pain is a prominent and early feature of axSpA. ${ }^{2,3}$ Pain is associated with functional limitation and disease activity which seriously affects the quality of life and mental health of patients. ${ }^{4,5}$ Eighty-to-ninety percent of axSpA patients consider pain to be the primary symptom to be treated and improved urgently. ${ }^{6}$ Moreover, the Assessment of SpondyloArthritis international Society (ASAS) defines improvement of symptoms, a reduction of pain as an important target in axSpA management. ${ }^{7}$

Received: October 08, 2020 Accepted: June 30, 2021 Published online: October 14, 2021

Correspondence: Li Li, PhD. Department of Nursing, Zhujiang Hospital, Southern Medical University, 253 Gongye Road M., Guangzhou 510282, China. Tel: 86-20-62783678 e-mail: Ili1@smu.edu.cn

\section{Citation:}

Deng S, He Y, Deng S, Sun E, Li L. Association between clinical characteristics and pain relief in patients with axial spondyloarthritis treated with non-steroidal anti-inflammatory drugs. Arch Rheumatol 2022;37(2):271-279.

(O2022 Turkish League Against Rheumatism. All rights reserved.

This is an open access article under the terms of the Creative Commons Attribution-NonCommercial License, which permits use, distribution and reproduction in any medium, provided the original work is properly cited and is not used for commercial purposes (http://creativecommons.org/licenses/by-nc/4.0/). 
Pain relief can be achieved by pharmacological and non-pharmacological treatments, in rare cases, including surgical methods. Non-steroidal anti-inflammatory drugs (NSAIDs) are recommended as the first-line drug treatment. They play an anti-inflammatory and analgesic role in the treatment of axSpA. ${ }^{8}$ Currently, NSAIDs are widely used in the treatment of pain in patients with axSpA. However, pain control is still insufficient in some patients, and about 30\% of patients still have no pain relief, despite the use of NSAIDs. ${ }^{9,10}$

Pain is affected by many factors, including physical, psychological and social pain. Swinnen et al. ${ }^{11}$ reported that women with axSpA exhibited a two-to-three-fold increased likelihood of widespread pain. Previous studies have suggested that neuropathic pain (NP) component contribute to higher pain severity in patients with axSpA. ${ }^{12-15}$ It is not clear which specific patient characteristics are associated with poor pain relief in patients treated with NSAIDs. Early prediction of individuals with poor pain relief allows for alternative treatment options to be considered.

In the present study, we aimed to evaluate pain relief in axSpA patients treated with NSAIDs and to investigate the relationship between demographic, clinical, and psychological characteristics and pain relief.

\section{PATIENTS AND METHODS}

This prospective study was conducted at The Third Affiliated Hospital of Southern Medical University, Department of Rheumatology and Immunology between February 2017 and December 2019. A total of 94 patients $(61$ males, 33 females; mean age: $28.3 \pm 8.1$ years; range, 14 to 54 years) who were diagnosed with axSpA according to the 2009 ASAS classification criteria and treated with NSAIDs were included. Inclusion criteria were as follows: a diagnosis of axSpA, reporting an average pain score from any joint $\geq 3$ on a 0-10 Numeric Rating Scale (NRS), and willing and able to participate in the study. Patients with other diseases, such as osteoarthritis, rheumatoid arthritis, gout, fibromyalgia, severe infection, diseases of mental health, surgical history or who were pregnant were excluded.

\section{Outcome measures}

Pain intensity was assessed by a 0-10 NRS $(0=$ no pain, $10=$ worst pain possible $)$. For each patient, we computed the raw change in the NRS score by subtracting the endpoint from the baseline. Then the percentage of pain relief (raw change/baseline $\times 100$ ) was calculated. A reduction of $30 \%$ in the NRS represented a clinically meaningful improvement. ${ }^{17,18}$ The patients were divided into two groups according to their percentage of pain relief. The relief group was defined as patients with a percentage of pain relief of $\geq 30 \%$, while the non-relief group with a percentage of pain relief of $<30 \%$.

The Douleur Neuropathique 4 Questionnaire (DN4) was used to assess the neuropathic component of pain. It is a 10 -item questionnaire consisting of both sensory descriptors and signs related to bedside sensory examination. ${ }^{19}$ Patients with a total score of $\geq 4$ were diagnosed with NP. The sensitivity and specificity of Chinese version of the DN4 were $82.7 \%$ and $97.1 \%$, respectively. ${ }^{20}$

A set of instruments was developed by the ASAS to measure health outcomes in axSpA. ${ }^{21,22}$ Disease activity was assessed using the erythrocyte sedimentation rate (ESR), C-reactive protein (CRP), Bath Ankylosing Spondylitis Disease Activity Index (BASDAI), and Patient Global Assessment (PGA). The BASDAI is consisted of six questions regarding fatigue, spinal pain, pain or swelling of peripheral joints, local tenderness, and morning stiffness. Each question is scored on an NRS, and the final BASDAI score with a range from 0 to 10 is calculated by summing the first four questions and the average of the last two questions, and dividing the result by five. The PGA was assessed by the following question: How active was your spondyloarthritis last week? The answer was recorded on a NRS, and the score ranges from 0 (not active) to 10 (very active). Higher BASDAI and PGA scores indicate a higher disease activity. Physical function was measured with the Bath Ankylosing Spondylitis Functional Index (BASFI). The BASFI includes 10 questions, which refers to difficulty in completing certain movements that reflect physical function in daily life. The BASDAI and BASFI have a good reliability in Chinese AS patients. The intraclass correlation coefficient (ICC) were 0.95 and 0.96 , respectively. ${ }^{23}$ Spinal mobility was measured by occiput-to-wall distance, 
finger to floor distance, chest expansion, and the Bath Ankylosing Spondylitis Metrology Index (BASMI). The BASMI is an objective tool including tragus-to-wall distance (TWD), modified Schobers' test, cervical rotation, lateral spinal flexion, and intermalleolar distance.

Pain catastrophizing refers to the individuals' tendency to focus excessively on pain sensations and exaggerate their threat value, and to feel helpless in their efforts to reduce or manage their pain. It was assessed using the Pain Catastrophizing Scale (PCS), which comprised of 13 items graded on $0-4$ Likert scale $(0=$ not at all, $4=$ all the time) ${ }^{24}$ The total score ranged from 0 to 52 , and the total score $\geq 30$ indicates that the patient has a tendency of pain catastrophizing. The Cronbach alpha of Chinese version was 0.91 , and ICC was $0.94 .^{25}$

Pain self-efficacy was measured using the Pain Self-Efficacy Questionnaire (PSEQ). It is a 10-item inventory designed to assess patients' confidence in coping with pain conditions on a scale of 0 (not at all confident) to 6 (completely confident), with higher scores indicating better pain self-efficacy. ${ }^{26}$ The Chinese version of PSEQ showed a good retest reliability (ICC 0.75) and high internal consistency (Cronbach alpha 0.93). ${ }^{27}$
All patients received regular NSAIDs for three months. Those with BASDAI score $\geq 4$ for more than four weeks, or patients with severe symptoms and who were expected to relieve symptoms as soon as possible, tumor necrosis factor inhibitor (TNFi) were also administered. ${ }^{28}$ The patients were evaluated by an independent observer at baseline and at the time of return to hospital after three-month treatment. Demographic and other clinical characteristics include age, sex, body mass index (BMI), employment, income, presence of smoking habits or drinking habits, human leukocyte antigen B27 (HLA-B27), peripheral joint pain, and prescribed medications were collected by questionnaires and from electronic medical records.

\section{Statistical analysis}

Statistical analysis was performed using the IBM SPSS version 20.0 software (IBM Corp., Armonk, NY, USA). Continuous variables were presented in mean \pm standard deviation (SD) or median (interquartile range [IQR], while categorical variables were presented in number and frequency. To study differences between two groups, independent samples t-test was performed for normally distributed variables, whereas the Mann-Whitney U test was conducted for skewed variables. Categorical variables were

Table 1. Comparisons of demographic characteristics between relief and non-relief groups $(n=94)$

\begin{tabular}{|c|c|c|c|c|c|c|c|c|c|c|c|}
\hline \multirow[b]{2}{*}{ Characteristics } & \multicolumn{3}{|c|}{ Relief ( $\mathrm{n}=61)$} & \multicolumn{3}{|c|}{ Non-relief ( $n=33$ ) } & \multicolumn{3}{|c|}{ Total } & \multirow[b]{2}{*}{$t / \chi^{2}$} & \multirow[b]{2}{*}{$p$} \\
\hline & $\mathrm{n}$ & $\%$ & Mean \pm SD & $\mathrm{n}$ & $\%$ & Mean \pm SD & $\mathrm{n}$ & $\%$ & Mean \pm SD & & \\
\hline Age (year) & & & $28.3 \pm 8.6$ & & & $28.2 \pm 6.6$ & & & $28.3 \pm 8.1$ & -0.048 & 0.962 \\
\hline $\begin{array}{l}\text { Sex } \\
\quad \text { Male } \\
\text { Female }\end{array}$ & $\begin{array}{l}47 \\
25\end{array}$ & $\begin{array}{l}65.3 \\
34.7\end{array}$ & & $\begin{array}{c}14 \\
8\end{array}$ & $\begin{array}{l}63.6 \\
36.4\end{array}$ & & $\begin{array}{l}61 \\
33\end{array}$ & $\begin{array}{l}64.9 \\
35.1\end{array}$ & & 0.020 & 0.888 \\
\hline $\begin{array}{l}\text { Body mass index }\left(\mathrm{kg} / \mathrm{m}^{2}\right) \\
\quad<18.5 \\
\quad 18.5 \sim 23.9 \\
\geq 24\end{array}$ & $\begin{array}{l}10 \\
37 \\
25\end{array}$ & $\begin{array}{l}66.7 \\
72.5 \\
89.3\end{array}$ & & $\begin{array}{c}5 \\
14 \\
3\end{array}$ & $\begin{array}{l}33.3 \\
27.5 \\
10.7\end{array}$ & & $\begin{array}{l}15 \\
51 \\
28\end{array}$ & $\begin{array}{l}16.0 \\
54.3 \\
29.8\end{array}$ & & 3.806 & 0.149 \\
\hline Current smokers & 17 & 23.6 & & 9 & 40.9 & & 26 & 27.7 & & 2.520 & 0.112 \\
\hline Current drinking & 8 & 11.1 & & 6 & 27.3 & & 14 & 14.9 & & 3.472 & 0.062 \\
\hline Full-time employment & 49 & 68.1 & & 13 & 59.1 & & 62 & 66.0 & & 0.603 & 0.437 \\
\hline $\begin{array}{l}\text { Average monthly family } \\
\text { income (¥) }\end{array}$ & & & & & & & & & & 2.702 & 0.440 \\
\hline$<1000$ & 8 & 11.1 & & 1 & 4.5 & & 9 & 9.6 & & & \\
\hline $1000-3000$ & 21 & 29.2 & & 8 & 36.4 & & 29 & 30.9 & & & \\
\hline $3000-6000$ & 21 & 29.2 & & 9 & 40.9 & & 30 & 31.9 & & & \\
\hline$>6000$ & 22 & 30.6 & & 4 & 18.2 & & 26 & 27.7 & & & \\
\hline
\end{tabular}

SD: Standard deviation; IQR: Interquartile range; ¥: The renminbi is the official currency of the People’s Republic of China; ${ }^{*} \mathrm{p}<0.05$. 


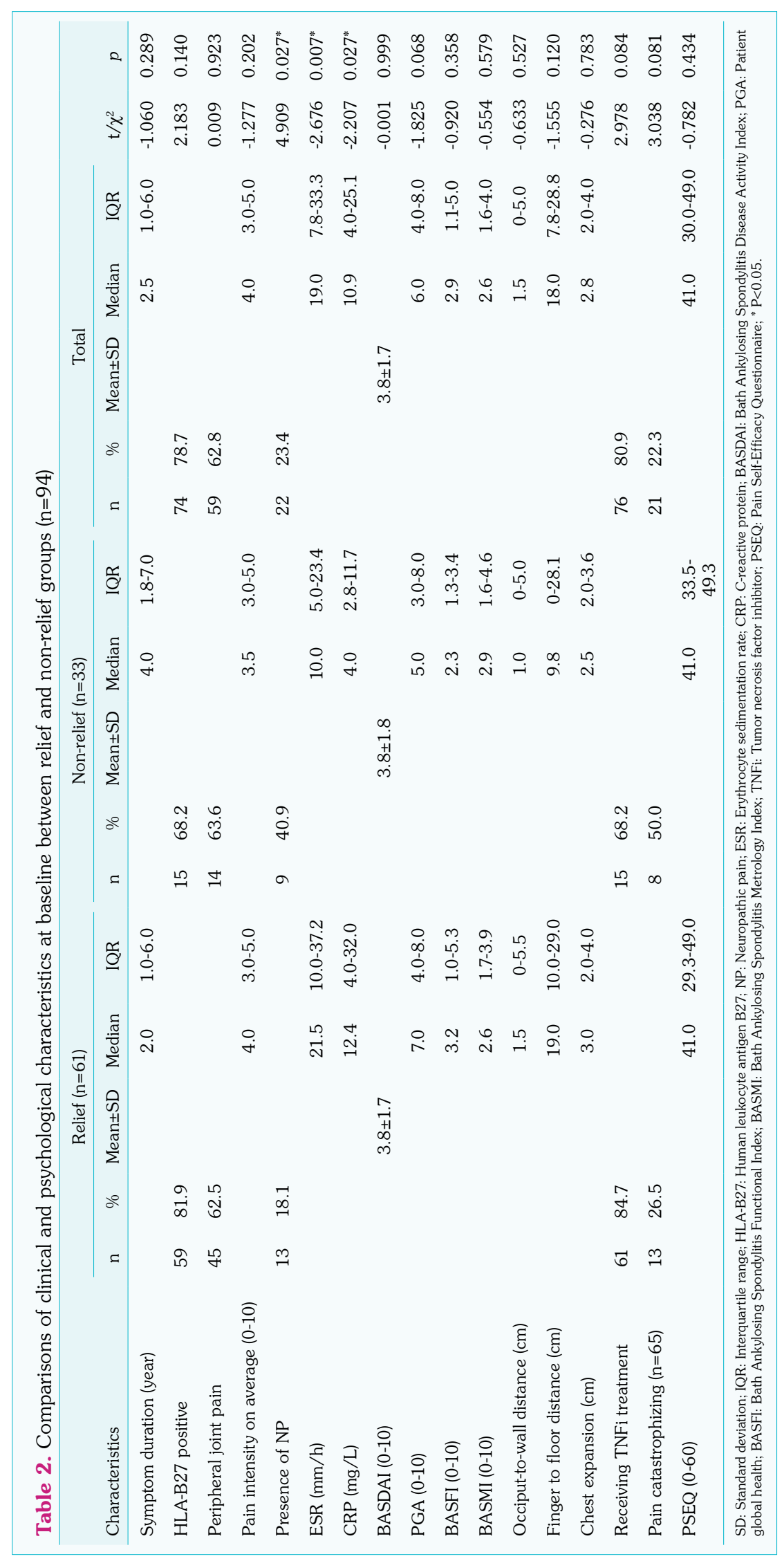


compared using the Chi-square test $\left(\chi^{2}\right)$ or Fisher exact test. Variables with a $p$ value of $<0.05$ in the univariate analysis were included in the multivariate analysis. A logistic regression analysis was conducted to analyze the variables that contributed to pain relief. A $p$ value of $<0.05$ was considered statistically significant.

\section{RESULTS}

Seventy-one $(75.5 \%)$ patients were newly diagnosed and never received NSAIDs at baseline. The remaining patients were taking NSAIDs unregularly or intermittently. After inclusion in the study, each patient received one type of NSAID for at least three months. Sixty-seven (71.3\%) patients were treated with celecoxib (200 mg daily or b.i.d.), 17 (18.1\%) with loxoprofen (60 mg daily or b.i.d.), 10 (10.6\%) with etoricoxib (60 mg daily). Seventy-six (80.9\%) patients were treated with combination of TNFi and NSAIDs. The TNFi was etanercept (25 mg or $50 \mathrm{mg}$ once a week), which was administered subcutaneously.

The median pain intensity in 94 patients with axSpA decreased from 4.0 (range, 3.0 to 5.0) to 2.0 (range, 0 to 3.0) at three months of follow-up. Seventy-two (76.6\%) patients achieved pain relief, and $22(23.4 \%)$ had no pain relief, with a NRS score of 1 (0-2) and 4 (3-5) out of 10 , respectively. The median change in NRS for two groups over three months was 3 (range, 2 to 4 ) and 0 (range, -1 to 0 ), respectively. The pain relief rates of celecoxib, loxoprofen, and etoricoxib were $77.6 \%, 76.5 \%$, and $70 \%$, respectively at three months of follow-up. The pain relief rate was not significantly different among all three NSAIDs $\left(\chi^{2}=0.281, p=0.869\right)$.
Demographic characteristics were compared between the relief and non-relief groups (Table 1). The patients without pain relief reported more smoking and alcohol drinking, although the difference was not statistically significant [40.9\% vs. $23.6 \%, \chi^{2}=2.520, p=0.112 ; 27.3 \%$ vs. $11.1 \%, \chi^{2}=3.472, \mathrm{p}=0.062$, respectively). There were no statistically significant differences between two groups in terms of age, sex, BMI, full-time employment, and average monthly family income ( $>0.05)$.

Statistically significant differences were found for ESR, CRP, and the presence of NP between the two groups $(p<0.05)$. There was no significant difference between the two groups in pain intensity on average, BASDAI, PGA, physical function, spinal mobility, receiving TNFi treatment, pain catastrophizing, and pain self-efficacy $(p>0.05)$. Patients with pain relief had significantly higher ESR and CRP values than those without pain relief (21.5 [10.0-37.2] vs. 10.0 [5.0-23.4], $\mathrm{Z}=-2.676, \mathrm{p}=0.007 ; 12.4$ [4.0-32.0] vs. 4.0 [2.8, 11.7], $\mathrm{Z}=-2.207, \mathrm{p}=0.027$, respectively) (Table 2). The median DN4 score of the relief group was 2 (range, 1 to 3 ), while that of non-relief group was 3 (range, 1 to 4). The percentage of patients diagnosed with NP was significantly higher in non-relief group than relief group $\left(40.9 \%\right.$ vs. $18.1 \%, \chi^{2}=4.909, p=0.027$, respectively) (Table 2). Subgroup analysis of TNFi-naive patients also showed patients with pain relief reported lower percentage of NP than those without pain relief $(9.1 \%$ vs. $57.1 \%$, $\chi^{2}=4.923, p=0.047$, respectively). Multivariate logistic regression analysis showed that NP was independently associated with pain relief. Patients with NP were less likely to achieve pain relief

Table 3. Logistic regression analysis of factors influencing pain relief in axSpA patients $(\mathrm{n}=94)$

\begin{tabular}{lccccc}
\hline Variable & $B$ & SE & $p$ & OR & $95 \%$ CI \\
\hline Presence of NP & 1.261 & 0.570 & 0.027 & 3.531 & $1.155-10.789$ \\
ESR & 0.039 & 0.025 & 0.114 & 1.040 & $0.991-1.091$ \\
CRP & 0.009 & 0.009 & 0.705 & 1.009 & $0.965-1.055$ \\
Constant & -1.885 & 1.102 & 0.087 & &
\end{tabular}

SE: Standard error; OR: Odds ratio; CI: Confidence interval; NP: Neuropathic pain; ESR: Erythrocyte sedimentation rate; CRP: C-reactive protein. 
$(p=0.027$, odds ratio [OR]: $3.531,95 \%$ confidence interval [CI]: 1.155-10.789) (Table 3).

\section{DISCUSSION}

The present study showed that pain relief was achieved in $76.6 \%$ of axSpA patients treated with NSAIDs, and there were about one-third of the patients whose pain could not be relieved, similar to previous studies. ${ }^{9,10} \mathrm{We}$ also found that the pain relief rate was not significantly different among celecoxib, loxoprofen, and etoricoxib, confirming previous results showing that various NSAIDs were equally effective in patients with axSpA. ${ }^{29}$

In our study, there was no significant difference in cigarette smoking or alcohol drinking between patients with pain relief and those without, unlike previous studies. Zhao et al. $^{30,31}$ reported that smoking and alcohol consumption were associated with the increased disease activity in patients with axSpA. Previous studies showed that smoking and drinking alcohol had a significant relationship with the progression of spinal structural damage. ${ }^{32,33}$ In the present study, we hypothesized that smoking and drinking adversely affected pain relief. The possible reason why we did not achieve this result may be due to insufficient sample size. Further studies are needed to evaluate, if quitting smoking and limiting alcohol could relieve pain and improve clinical outcomes more effectively.

Acute phase reactants such as ESR and CRP are considered important laboratory indicators for monitoring disease activity of axSpA patients. Patients with elevated ESR or CRP may have more severe pain and prolonged morning stiffness. Our study showed that patients with pain relief reported higher baseline ESR and CRP values than those without pain relief. This finding suggests that inflammatory low back pain responds well to NSAIDs therapy. Previous studies reported that the continuous use of NSAIDs in patients with an elevated CRP results in reduced progression of structural damage in the spine compared to on-demand use only. ${ }^{34}$ However, an elevated ESR or CRP is only present in 30 to $40 \%$ of the patients, and it is necessary to realize that a normal value does not preclude the presence of inflammation. ${ }^{22}$ Considering the possible risks and benefits, NSAIDs should be prescribed if the patient has other symptoms of inflammatory low back pain.

The present study showed that $23.4 \%$ of the patients with axSpA had NP, which is slightly higher than previous studies. ${ }^{12,13,15}$ Patients with no pain relief reported higher rates of NP, and the presence of NP predicts poor pain relief in axSpA patients treated with NSAIDs. Of note, NSAIDs reduce the sensitivity of local pain receptors to inflammatory substances by blocking cyclooxygenase, interfering with prostaglandin synthesis. ${ }^{35}$ Patients with NP would be less likely to respond to NSAIDs. It referred medical staff that NP should be assessed before treatment. Considering the possible side effects, NSAIDs should not be used to treat pain in patients with NP, and alternative drugs should be selected. Andrade et al. ${ }^{36}$ reported that TNFi can alleviate experimentally induced NP through the modulation of TNF receptor expression. Wu et al. ${ }^{37}$ reported that TNFi attenuated the NP component of AS in addition to reversing sensory loss and improving lateral spinal mobility. The diagnosis and treatment of NP remain a challenge, due to its complex mechanism. ${ }^{38}$ Further studies on the pathogenesis and the management of NP in axSpA patients are warranted.

Our findings indicated that the percentage of patients who received TNFi was higher in patients with pain relief than in those without, although the difference was not statistically significant. $\mathrm{Wu}$ et al. ${ }^{37}$ studied the brain effects related to the change in pain after TNFi treatment, and the results showed that TNFi treatment produced changes in brain areas implicated in sensory, motor, affective, and cognitive functions. Pain intensity reduction was associated with cortical thinning of the secondary somatosensory cortex. Moreover, previous evidence has suggested that combination therapy with TNFi plus NSAIDs is superior to NSAIDs monotherapy for reaching ASAS partial remission in patients with early, active axSpA. ${ }^{39,40}$ These findings suggest that TNFi can be considered as the first-line treatment for eligible patients.

It is known that pain catastrophizing, pain selfefficacy are related to pain intensity in patients with chronic pain..$^{41-43}$ Rosenberg et al. ${ }^{44}$ reported that patients with greater pain catastrophizing 
were more likely to report lower pain relief after spinal cord stimulation. Tanaka et al. $^{45}$ also reported that pain catastrophizing, and selfefficacy were predictors of pain relief in patients with knee osteoarthritis receiving conservative treatment. However, there were no significant difference in catastrophizing and self-efficacy between two groups in our study. The discrepancy may result from different outcome measures and the heterogeneity of research subjects. This needs to be further verified by cohort study.

There are several limitations to our study. First, we did not exclude those patients with TNFi and NSAIDs, which may have a confounding effect on the results. Second, potential predictors included in the study may not be comprehensive enough, patients' exercise habits, and social support were not studied. Third, only a screening tool (DN4) was used to identify neuropathic component of pain. Although the DN4 has been validated in several studies as a sensitive and specific tool for the detection of NP, additional tests such as somatosensory testing are needed to confirm NP.

In conclusion, pain relief is still insufficient in some axSpA patients, despite the administration of NSAIDs. The presence of NP seems to be significantly associated with poor pain relief. Alternative medications rather than NSAIDs are needed to achieve optimal pain relief, when NP is diagnosed.

Ethics Committee Approval: The study protocol was approved by the The Third Affiliated Hospital of Southern Medical University Ethics Committee (No: 201608003). The study was conducted in accordance with the principles of the Declaration of Helsinki.

Patient Consent for Publication: A written informed consent was obtained from each patient.

Data Sharing Statement: The data that support the findings of this study are available from the corresponding author upon reasonable request.

Author Contributions: The design of the study, collection and analysis of the data, interpretation of the results, drafting and revising the manuscript: S.D.; The design of the study, collection of the data, interpretation of the results, and revising the manuscript: Y.H.; Collection and analysis of the data, interpretation of the results, and revising the manuscript: S.D.; The design of the study, interpretation of the results, and revising the manuscript: E.S.; The design of the study, interpretation of the results, drafting and revising the manuscript: L.L.
Conflict of Interest: The authors declared no conflicts of interest with respect to the authorship and/or publication of this article.

Funding: The authors received no financial support for the research and/or authorship of this article.

\section{REFERENCES}

1. Sieper J, Poddubnyy D. Axial spondyloarthritis. Lancet 2017;390:73-84.

2. Bagcivan G, Cinar FI, Cinar M, Oflaz F, Uzun S, Pay S. Living with pain in ankylosing spondylitis: A qualitative study. Contemp Nurse 2015;51:13547.

3. Bidad K, Gracey E, Hemington KS, Mapplebeck JCS, Davis KD, Inman RD. Pain in ankylosing spondylitis: A neuro-immune collaboration. Nat Rev Rheumatol 2017;13:410-20.

4. Durmus D, Sarisoy G, Alayli G, Kesmen H, Çetin E, Bilgici $A$, et al. Psychiatric symptoms in ankylosing spondylitis: Their relationship with disease activity, functional capacity, pain and fatigue. Compr Psychiatry 2015;62:170-7.

5. Kwan YH, Fong W, Cheng GHL, Phang JK, Leung YY, Lui NL, et al. The mediating role of pain and function in the association between stiffness and quality of life in patients with axial spondyloarthritis. Semin Arthritis Rheum 2019;49:377-80.

6. Heiberg T, Lie E, van der Heijde D, Kvien TK. Sleep problems are of higher priority for improvement for patients with ankylosing spondylitis than for patients with other inflammatory arthropathies. Ann Rheum Dis 2011;70:872-3.

7. Kiltz U, Baraliakos X, Regel A, Bühring B, Braun J. Causes of pain in patients with axial spondyloarthritis. Clin Exp Rheumatol 2017;35 Suppl 107:102-7.

8. van der Heijde D, Ramiro S, Landewé R, Baraliakos X, Van den Bosch F, Sepriano A, et al. 2016 update of the ASAS-EULAR management recommendations for axial spondyloarthritis. Ann Rheum Dis 2017;76:978-91.

9. Poddubnyy D. Axial spondyloarthritis: Is there a treatment of choice? Ther Adv Musculoskelet Dis 2013;5:45-54.

10. Toussirot E. Pharmacological management of axial spondyloarthritis in adults. Expert Opin Pharmacother 2019;20:1483-91.

11. Swinnen TW, Westhovens R, Dankaerts W, de Vlam $\mathrm{K}$. Widespread pain in axial spondyloarthritis: Clinical importance and gender differences. Arthritis Res Ther 2018;20:156.

12. Ji $\mathrm{Y}, \mathrm{He} \mathrm{Y}$, Nian $\mathrm{X}$, Sun $\mathrm{E}$, Li L. Inflammatory or Neuropathic Pain: Characteristics and their relationships with disease activity and functional status in axial spondyloarthritis patients. Pain Med 2019;20:882-8. 
13. Geler-Külcü D, Batıbay S, Öztürk G, Mesci N. The association of neuropathic pain and disease activity, functional level, and quality of life in patients with ankylosing spondylitis: A cross-sectional study. Turk J Med Sci 2018;48:257-65.

14. Gok K, Cengiz G, Erol K, Ozgocmen S. Neuropathic pain component in axial spondyloarthritis and the influence on disease burden. $\mathrm{J}$ Clin Rheumatol 2018;24:324-7.

15. Choi JH, Lee SH, Kim HR, Lee KA. Association of neuropathic-like pain characteristics with clinical and radiographic features in patients with ankylosing spondylitis. Clin Rheumatol 2018;37:3077-86.

16. Rudwaleit $\mathrm{M}$, van der Heijde $\mathrm{D}$, Landewé $\mathrm{R}$, Listing $\mathrm{J}$, Akkoc N, Brandt $\mathrm{J}$, et al. The development of Assessment of SpondyloArthritis international society classification criteria for axial spondyloarthritis (part II): validation and final selection. Ann Rheum Dis 2009;68:777-83.

17. Farrar JT, Young JP Jr, LaMoreaux L, Werth JL, Poole MR. Clinical importance of changes in chronic pain intensity measured on an 11-point numerical pain rating scale. Pain 2001;94:149-58.

18. Ostelo RW, Deyo RA, Stratford P, Waddell G, Croft $\mathrm{P}$, Von Korff $\mathrm{M}$, et al. Interpreting change scores for pain and functional status in low back pain: Towards international consensus regarding minimal important change. Spine (Phila Pa 1976) 2008;33:90-4.

19. Bouhassira D, Attal N, Alchaar H, Boureau F, Brochet $\mathrm{B}$, Bruxelle $\mathrm{J}$, et al. Comparison of pain syndromes associated with nervous or somatic lesions and development of a new neuropathic pain diagnostic questionnaire (DN4). Pain 2005;114:29-36.

20. Chen J, Li L. Validation of neuropathic pain assessment tools among Chinese patients with painful diabetic peripheral neuropathy. International Journal of Nursing Sciences 2016;3:139-45.

21. Sieper J, Rudwaleit M, Baraliakos X, Brandt J, Braun J, Burgos-Vargas R, et al. The Assessment of SpondyloArthritis international Society (ASAS) handbook: A guide to assess spondyloarthritis. Ann Rheum Dis 2009;68 Suppl 2:ii1-44.

22. Landewé R, van Tubergen A. Clinical tools to assess and monitor spondyloarthritis. Curr Rheumatol Rep 2015;17:47.

23. Lin Z, Gu J, He P, Gao J, Zuo X, Ye Z, et al. Multicenter validation of the value of BASFI and BASDAI in Chinese ankylosing spondylitis and undifferentiated spondyloarthropathy patients. Rheumatol Int 2011;31:233-8.

24. Sullivan MJL, Bishop SR, Pivik J. The pain catastrophizing scale: Development and validation. Psychological Assessment 1995;7:524-32.

25. Xu X, Wei X, Wang F, Liu J, Chen H, Xiong Y, Li M. Validation of a simplified chinese version of the pain catastrophizing scale and an exploration of the factors predicting catastrophizing in pain clinic patients. Pain Physician 2015;18:E1059-72.
26. Nicholas MK. The pain self-efficacy questionnaire: Taking pain into account. Eur J Pain 2007;11:153-63.

27. Lim HS, Chen PP, Wong TC, Gin T, Wong E, Chan IS, et al. Validation of the Chinese version of pain self-efficacy questionnaire. Anesth Analg 2007;104:918-23.

28. Chinese Research Hospital Association. Expert consensus on diagnosis and treatment of axial spondyloarthritis[J]. Chin J Joint Surg (Electronic Edition) 2019;13:261-6.

29. Kroon FP, van der Burg LR, Ramiro S, Landewé RB, Buchbinder R, Falzon L, et al. Non-Steroidal Anti-Inflammatory Drugs (NSAIDs) for axial spondyloarthritis (ankylosing spondylitis and nonradiographic axial spondyloarthritis). Cochrane Database Syst Rev 2015;(7):CD010952.

30. Zhao S, Challoner B, Khattak M, Moots RJ, Goodson NJ. Increasing smoking intensity is associated with increased disease activity in axial spondyloarthritis. Rheumatol Int 2017;37:239-44.

31. Zhao S, Thong D, Duffield SJ, Hughes D, Goodson NJ. Alcohol and disease activity in axial spondyloarthritis: A cross-sectional study. Rheumatol Int 2018;38:375-81.

32. Villaverde-García V, Cobo-Ibáñez T, CandelasRodríguez G, Seoane-Mato D, Campo-Fontecha PDD, Guerra $\mathrm{M}$, et al. The effect of smoking on clinical and structural damage in patients with axial spondyloarthritis: A systematic literature review. Semin Arthritis Rheum 2017;46:569-83.

33. Min HK, Lee J, Ju JH, Park SH, Kwok SK. Alcohol consumption as a predictor of the progression of spinal structural damage in axial spondyloarthritis: Data from the Catholic Axial Spondyloarthritis COhort (CASCO). Arthritis Res Ther 2019;21:187.

34. Kroon F, Landewé R, Dougados M, van der Heijde D. Continuous NSAID use reverts the effects of inflammation on radiographic progression in patients with ankylosing spondylitis. Ann Rheum Dis 2012;71:1623-9.

35. Wang R, Dasgupta A, Ward MM. Comparative efficacy of non-steroidal anti-inflammatory drugs in ankylosing spondylitis: A Bayesian network meta-analysis of clinical trials. Ann Rheum Dis 2016;75:1152-60.

36. Andrade P, Hoogland G, Del Rosario JS, Steinbusch HW, Visser-Vandewalle V, Daemen MA. Tumor necrosis factor- $\alpha$ inhibitors alleviation of experimentally induced neuropathic pain is associated with modulation of TNF receptor expression. J Neurosci Res 2014;92:1490-8.

37. Wu Q, Inman RD, Davis KD. Tumor necrosis factor inhibitor therapy in ankylosing spondylitis: Differential effects on pain and fatigue and brain correlates. Pain 2015;156:297-304.

38. Nascimento OJ, Pessoa BL, Orsini M, Ribeiro P, Davidovich E, Pupe C, et al. Neuropathic pain treatment: still a challenge. Neurol Int 2016;8:6322. 
39. Sieper J, Lenaerts J, Wollenhaupt J, Rudwaleit M, Mazurov VI, Myasoutova L, et al. Efficacy and safety of infliximab plus naproxen versus naproxen alone in patients with early, active axial spondyloarthritis: Results from the double-blind, placebo-controlled INFAST study, Part 1. Ann Rheum Dis 2014;73:101-7.

40. Ward MM, Deodhar A, Gensler LS, Dubreuil M, Yu D, Khan MA, et al. 2019 Update of the American College of Rheumatology/Spondylitis Association of America/spondyloarthritis research and treatment network recommendations for the treatment of ankylosing spondylitis and nonradiographic axial spondyloarthritis. Arthritis Rheumatol 2019;71:1599-613.

41. Martinez-Calderon J, Jensen MP, Morales-Asencio JM, Luque-Suarez A. Pain catastrophizing and function In individuals with chronic musculoskeletal pain: A systematic review and meta-analysis. Clin $\mathrm{J}$ Pain 2019;35:279-93.
42. Ferrari S, Chiarotto A, Pellizzer M, Vanti C, Monticone M. Pain self-efficacy and fear of movement are similarly associated with pain intensity and disability in italian patients with chronic low back pain. Pain Pract 2016;16:1040-7.

43. Crijns TJ, Liu TC, Ring D, Bozic KJ, Koenig K. Influence of patient activation, pain self-efficacy, and resilience on pain intensity and magnitude of limitations in patients with hip and knee arthritis. $J$ Surg Orthop Adv 2019;28:48-52.

44. Rosenberg JC, Schultz DM, Duarte LE, Rosen SM, Raza A. Increased pain catastrophizing associated with lower pain relief during spinal cord stimulation: Results from a large post-market study. Neuromodulation 2015;18:277-84.

45. Tanaka R, Hirohama K, Kurashige Y, Mito K, Miyamoto S, Masuda R, et al. Prediction models considering psychological factors to identify pain relief in conservative treatment of people with knee osteoarthritis: A multicenter, prospective cohort study. J Orthop Sci 2020;25:618-26. 